\title{
Cytokine Profile and Its Correction by Immunomodulators in Experimental Bronchopulmonary Inflammation in Rats
}

\author{
Marina A. Darenskaya, $\mathrm{PhD}, \mathrm{ScD}^{1 *}$; Evgeniy V. Mokrenko, $\mathrm{PhD}^{2}$; Petr D. Shabanov, \\ $\mathrm{PhD}, \mathrm{ScD}^{3}$; Maria I. Suslikova, $\mathrm{PhD}^{2}$; Igor Yu. Kostritsky²; Ivan S. Goncharov²; Mark E. \\ Mokrenko²; Evgeniy I. Kostritsky²; Yulia O. Sinyova ${ }^{4}$; Lyubov I. Kolesnikova, PhD, ScD, \\ Academician of the RAS ${ }^{1}$; Sergey I. Kolesnikov, $\mathrm{PhD}, \mathrm{ScD}$, Academician of the RAS ${ }^{1,5}$

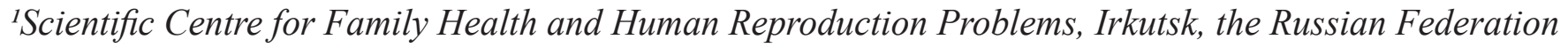 \\ 'Irkutsk State Medical University, Irkutsk, the Russian Federation \\ ${ }^{3}$ S. M. Kirov Military Medical Academy, Saint Petersburg, the Russian Federation \\ ${ }^{4}$ Irkutsk National Research Technical University, Irkutsk, the Russian Federation \\ ${ }^{5}$ M.V. Lomonosov Moscow State University, Moscow, the Russian Federation
}

\begin{abstract}
The aim of this study was to assess the changes in the levels of the blood serum pro- and anti-inflammatory cytokines in rats with experimental bronchopneumonia and after administration of immunomodulators.

Materials and Methods: Research was carried out on mature male Wistar rats ( $\mathrm{n}=111)$, weighing 220-250g. The bronchopulmonary inflammation in the rats was modeled by administration of $0.1 \mathrm{ml}$ of gum turpentine in the rats' trachea under etherization. All rats were divided into four groups: Group 1 included intact animals $(\mathrm{n}=18)$; Group 2 included animals having bronchopneumonia ( $\mathrm{n}=19)$; Group 3 included animals having bronchopneumonia treated with Krezacin ( $\mathrm{n}=15)$; Group 4 included animals having bronchopneumonia treated with Metaprot $(\mathrm{n}=16)$. Right after the operation and for the next 5 days, a solution of one of the test immunomodulators was injected (once a day) abdominally in the experimental animals: $25 \mathrm{mg} / \mathrm{kg}$ of Krezacin or $25 \mathrm{mg} / \mathrm{kg}$ of Metaprot. On Day 5 of the experiment, the animals were decapitated under anesthesia and blood samples were collected. The concentration of cytokines in the blood was determined by the flow immunofluorometry method with the device Bio-RadLaboratories (USA).

Results: The administration of Krezacin in animals with bronchopneumonia, in comparison with untreated animals, was accompanied by a statistically significant increase in the levels of IL-1 $\beta$ (by 3.43 times), IL-2 (by 1.95 times), INF- $\gamma$ (by 3.29 times), and MCP-1 (by 2.07 times) and a decrease in the levels of TNF $\alpha$ (by 1.85 times) and IL-6 (by 2.20 times). Administration of Krezacin increased anti-inflammatory cytokines considerably: IL-4 by 5.22 times and IL-10 by 2.41 times. Analysis of results after administration of Metaprot demonstrates an increase in the levels of IL-1 $\beta$ (by 2.57 times), IL-2 (by 2 times), INF- $\gamma$ (by 3.21 times), and MCP-1 (by 1.98 times) and a decrease in the levels of TNF $\alpha$ (by 2.17 times) and IL-6 (by 2.5 times), compared to data on untreated animals. Anti-inflammatory cytokines also increased greatly: IL-4 by 5.3 times and IL-10 by 3.71 times.

Conclusion: The results obtained show that investigated preparations reduce the severity and intensity of bronchopneumonia in rats. Krezacin and Metaprot demonstrate the properties of true immunomodulators, increasing protective properties of cytokines and providing the adaptive response of the body in severe bronchopulmonary pathology. (International Journal of Biomedicine. 2019;9(4):361-365.)
\end{abstract}

Key Words: experimental bronchopneumonia $\bullet$ rats $\bullet$ cytokines $\bullet$ immunomodulators

\section{Abbreviations}

IL, interleukin; INF, interferone; MCP-1, monocyte chemotactic protein 1; TNF, tumor necrosis factor; SB RAS - Siberian branch of the Academy of Sciences. 


\section{Introduction}

Upper respiratory tract infections are considered a serious health problem due to high prevalence, complex clinical course and severe complications of disease. ${ }^{(1)}$ As a rule, the treatment efficacy of acute bronchopulmonary diseases, particularly pneumonia, depends on adequate antibacterial treatment as well as the presence of secondary immunodeficiency status. ${ }^{(2,3)}$

It should be noted that diverse antibacterial therapies are becoming less effective against a wide range of pneumonia pathogens, resulting in long-term morbidity and chronicity. ${ }^{(4)} \mathrm{As}$ noted, acute bronchopulmonary diseases are accompanied by a progression of chronic hypoxia, alterations in immune response, and the development of oxidative stress. ${ }^{(5,6)}$ The severity of this kind disease necessitates the development and research of new types of antihypoxic and immunotropic medicines. ${ }^{(7-11)}$ Krezacin (hydroxyethylammonium methylphenoxyacetate) and Metaprot (ethylthiobenzimidazole hydrobromide monohydrate) were created in Russia in the middle of the last century and proved to have antihypoxic, energy-stabilizing (ergotropic) and immunomodulating properties. ${ }^{(12-16)}$ However, studies of these medicines regarding bronchopulmonary diseases have not been carried out.

In fact, inflammatory and immune reactions are the result of interactions among numerous body systems, where cytokines (interleukin, colony-stimulating and growth factors, interferons, chemokines, etc.) are an connecting link between them. ${ }^{17-}$ ${ }^{22)}$ Different cytokines possessing pro-inflammatory or antiinflammatory effects not only perform a regulatory function within the immune system, but also provide multicomponent connections with the nervous and endocrine systems. ${ }^{(23)}$

Thus, it is rather important to investigate the presently unknown pathogenetic mechanisms of the inflammatory process in the bronchopulmonary tissue and the protective effect of immunomodulators, focusing on changes in the cytokine blood levels of the experimental animals. In regard to the above, the aim of this study was to assess the changes in the levels of the blood serum pro- and anti-inflammatory cytokines in rats with experimental bronchopneumonia and after administration of immunomodulators.

\section{Material and Methods}

Research was carried out on mature male Wistar rats $(n=111)$, weighing 220-250 g. The bronchopulmonary inflammation in the rats was modeled by administration of 0.1 $\mathrm{ml}$ of gum turpentine in the rats' trachea under etherization. Animals in the vivarium were kept in cages at a temperature of $20^{\circ}-22^{\circ} \mathrm{C}$, without limitation of mobility, with free access to water with an adjustable light schedule (12 hours - light, 12 hours - darkness).

All rats were divided into four groups: Group 1 included intact animals $(\mathrm{n}=18)$; Group 2 included animals having bronchopneumonia $(n=19)$; Group 3 included animals having bronchopneumonia treated with Krezacin $(n=15)$; Group 4 included animals having bronchopneumonia treated with Metaprot $(\mathrm{n}=16)$.
Right after the operation and for the next 5 days, a solution of one of the test immunomodulators was injected (once a day) abdominally in the experimental animals: $25 \mathrm{mg}$ / $\mathrm{kg}$ of Krezacin or $25 \mathrm{mg} / \mathrm{kg}$ of Metaprot. The choice of dose level was determined by previous studies and evidence of the effectiveness of the medicines in these doses. ${ }^{(8,11)}$ On Day 5 of the experiment, the animals were decapitated under anesthesia and blood samples were collected. Blood serum prepared by centrifugation at $2500 \mathrm{rpm}$ for 20 minutes at $+4^{\circ} \mathrm{C}$ was frozen and stored at $-20^{\circ} \mathrm{C}$ until testing.

The concentration of cytokines in the blood was determined by the flow immunofluorometry method with the device Bio-RadLaboratories (USA). MilliplexMapRatCitokine/ Chemokine sets were used in accordance with the instructions of the producing firm. The method is based on the specific binding of the studied cytokines to the solid phase in suspension of polystyrene granules with a fluorescent label and is conjugated to the appropriate anticytokine monoclonal antibodies. The results were evaluated by the flow fluorimeter, where borders are automatically divided by the specific fluorescence of their own labels. Using standard calibration dilutions, the concentration of the studied cytokines in the tested samples was calculated automatically by the Bio-plex Manager computer program and was expressed in $\mathrm{pcg} / \mathrm{ml}$.

For the treatment of bronchopneumonia in rats, Krezacin and Metaprot were used. Krezacin was invented at the A.E. Favorsky Irkutsk Institute of Chemistry SB RAS in the 1990s; after that it was actively studied at the S.N. Kirov Military Medical Academy (Saint Petersburg). Metaprot was created as an adaptogen for military medicine exclusively in the 1970s. Both preparations are classified as phytohormones and are highly effective adaptogens; they act as stress protectors and have an anti-toxic effect. ${ }^{(13)}$

The work with animals was carried out in accordance with the principles of humanism laid down in the directives of the European Community (86/609/EEC) and the Declaration of Helsinki, in accordance with the "Animal experimentation legislations". The study was approved by the Local Ethic Committee of the S.M. Kirov Military Medical Academy.

Statistical analysis was performed using the Statistica 6.1 software package (Stat-Soft Inc., USA). The normality of distribution of continuous variables was tested by the Kolmogorov-Smirnov test with the Lilliefors correction and Shapiro-Wilk test. An F-test was used to test if the variances of two populations are equal. Differences of continuous variables departing from the normal distribution, even after transformation, were tested by the Mann-Whitney $U$-test. A probability value of $P \leq 0.05$ was considered statistically significant.

\section{Results and Discussion}

The modeling of experimental bronchopulmonary inflammation in the rats was accompanied by considerable changes in blood serum pro- and anti-inflammatory cytokines (Fig.1). Therefore, a statistically significant decrease in the levels of IL-2 (by 1.85 times), IFN- $\gamma$ (by 1.43 times) and MCP-1 (by 2.07 times). In addition, levels of TNF $\alpha$ (by 3.16 
times) and IL-6 (by 4.68 times) were greatly increased. The concentration of anti-inflammatory cytokines IL-4 and IL10 was notable decreased - by 1.78 times and by 1.71 times, respectively (Fig.2).

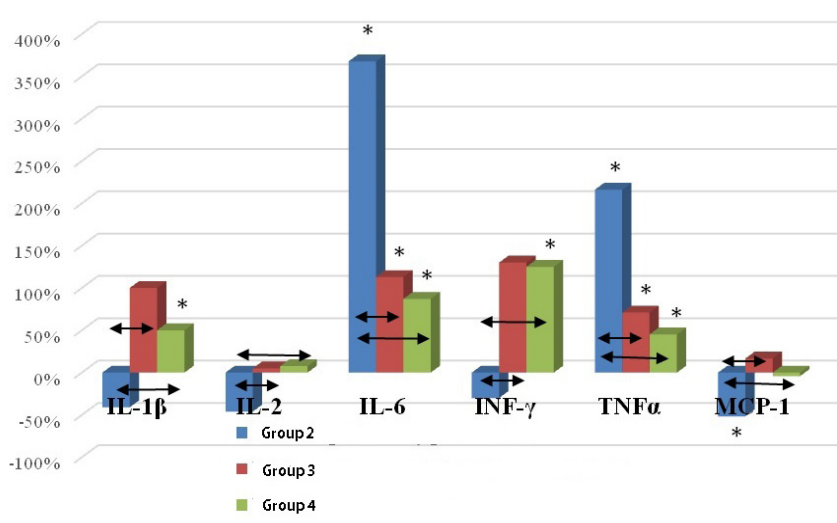

Fig. 1. Changes in the pro-inflammatory cytokine levels in rats with bronchopneumonia treated by different immunomodulators. * - statistically significant differences compared to intact animals (values are taken as $0 \%$ ); $\leftrightarrow$ - statistically significant differences between groups

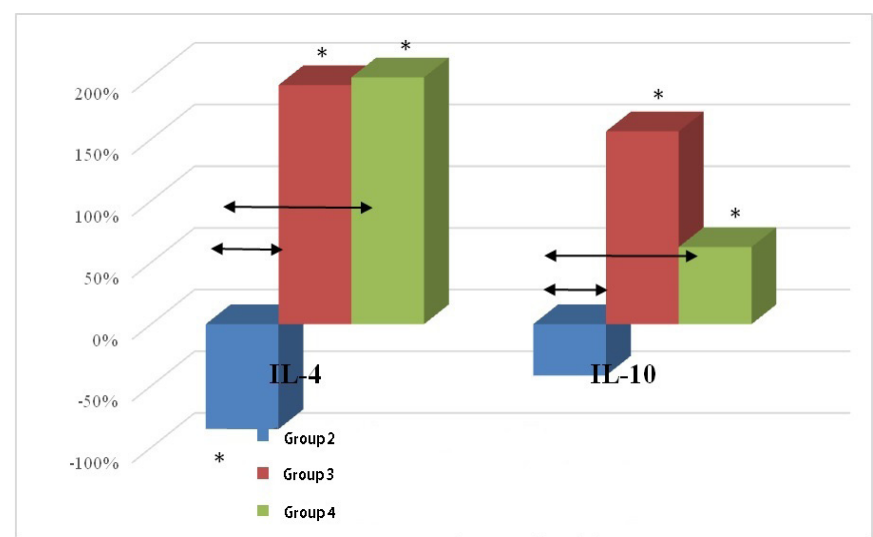

Fig. 2. Changes in the anti-inflammatory cytokine levels in rats with bronchopneumonia treated by different immunomodulators. * - statistically significant differences compared to intact animals (values are taken as $0 \%$ ); $\leftrightarrow$ - statistically significant differences between groups

The decreased concentration of both pro-inflammatory and anti-inflammatory (IL-4, IL-10) factors in blood in rats with inflammation stands out. At the same time, the levels of TNF $\alpha$ and IL-6 counts were increased.

Findings indicate that experimental bronchopneumonia in rats can be the cause of secondary immunodeficiency development and acute depression of immunoregulatory functions of cytokines, which are responsible both for the development of inflammation and for limiting its severity. Such disarrangement of the cascade process in regulating properties in cytokines that act upon integrating the nervous, endocrine and immunological mechanisms of inflammation certainly points to the intensity and severity of bronchopulmonary inflammation, as well its destructive nature.
This finding is also supported by the fact that TNF $\alpha$ blood content increased more than 3 times and TNF $\alpha$ was considered as the strong factor of overproliferation and apoptosis. ${ }^{(1,12)}$ TNF $\alpha$ is an inducer for progression of both local and systemic inflammation and promotes as well the synthesis of a wide range of pro-inflammatory cytokines that worsen tissue damage. In addition to pro-inflammatory cytokines, TNF $\alpha$ also increases lipid signal transduction mediators such as prostaglandins and platelet activating factor. TNF $\alpha$ governs cell survival signaling pathways, proliferation and regulates metabolic processes. ${ }^{(25)}$ Moreover, almost a 5-fold increase of IL-6 level evidences the high severity and intensity of the systemic inflammatory process, because IL-6 is known as the "cytokine of damage," produced not only by monocytes, but also by $\mathrm{T}$ cells, macrophages, fibroblasts, and endothelial cells. ${ }^{(17,26)}$ Affected by inflammatory mediators, the synthesis of this cytokine begins even at the early stages of the inflammation. During the later stages, it induces the differentiation of lymphocytes, as well as T-killer precursors into mature effector cells, which ensure target cells lysis, while stimulating the production of other interleukins. ${ }^{(27)}$ In addition, IL-6 also activates T lymphocytes with the formation of plasma cells and antibodies. ${ }^{(28,29)}$ In high doses it modulates the expression of hepatocyte-specific genes, which encode proteins of the acute phase of inflammation and, thereby, provide the transformation of inflammation into a chronic form. ${ }^{(30,31)}$

The administration of Kezacin in animals with bronchopneumonia, in comparison with untreated animals, was accompanied by a statistically significant increase in the levels of IL-1 $\beta$ (by 3.43 times), IL-2 (by 1.95 times), INF- $\gamma$ (by 3.29 times), and MCP-1 (by 2.07 times) and a decrease in the levels of TNF $\alpha$ (by 1.85 times) and IL-6 (by 2.20 times) (Fig.1). Administration of Krezacin increased antiinflammatory cytokines considerably: IL-4 by 5.22 times and IL-10 by 2.41 times (Fig.2).

Analysis of results after administration of Metaprot demonstrates an increase in the levels of IL-1 $\beta$ (by 2.57 times), IL-2 (by 2 times), INF- $\gamma$ (by 3.21 times), and MCP-1 (by 1.98 times) and a decrease in the levels of TNF $\alpha$ (by 2.17 times) and IL-6 (by 2.5 times), compared to data on untreated animals (Fig.1). Anti-inflammatory cytokines also increased greatly: IL-4 by 5.3 times and IL-10 by 3.71 times (Fig.2).

The administration of used immunomodulators considerably limits the impact of the pathological process influencing the cytokines levels in rats' blood. Thus, the levels of pro-inflammatory cytokines IL- $1 \beta$, IL-2, chemokine MCP1 , and INF- $\alpha$, as well as anti-inflammatory cytokines IL-4, IL-10 increased significantly. That indicated not only a partial recovery of immunoregulatory function, but also cytokineproducing properties of $\mathrm{B}$ cells, $\mathrm{T}$ helper 1 cells and $\mathrm{T}$ helper 2 cells.

It should be noted that immunomodulators used in this study limited the cytotoxic action of IL-6, and therefore can be considered as perspective anti-inflammatory mediators. Apparently, the recovery of the production and escalated levels of anti-inflammatory cytokines IL-4 and IL-10, after administration of immunomodulators, can be considered as a sanogenetic action of Krezacin and Metaprot. 
The administration of immunomodulators also decreased animal mortality rate. The survival rate in untreated bronchopneumonia was $48 \%$, but after administration of Krezacin and Metaprot it was $65 \%$ and $60 \%$, respectively.

\section{Conclusion}

The results obtained show that investigated preparations reduce the severity and intensity of bronchopneumonia in rats. They demonstrate the properties of true immunomodulators, increasing protective properties of cytokines and providing the adaptive response of the body in severe bronchopulmonary pathology.

\section{Competing Interests} interests.

The authors declare that they have no competing

\section{References}

1. Rendon A, Rendon-Ramirez EJ, Rosas-Taraco AG. Relevant Cytokines in the Management of CommunityAcquired Pneumonia. Curr Infect Dis Rep. 2016;18(3):10. doi: 10.1007/s11908-016-0516-y.

2. Wiemken TL, Kelley RR, Fernandez-Botran R, Mattingly WA, Arnold FW, Furmanek SP, et al. Using cluster analysis of cytokines to identify patterns of inflammation in hospitalized patients with community-acquired pneumonia: a pilot study. Univ Louisville J Respir Infect. 2017;1(1):3-11. doi: 10.18297/ jri/vol1/iss $1 / 1 /$.

3. Wu WF, Fang Q, He GJ. Efficacy of corticosteroid treatment for severe community-acquired pneumonia: A meta-analysis. Am J Emerg Med. 2018;36(2):179-184. doi: 10.1016/j.ajem.2017.07.050.

4. Stulik L, Hudcova J, Craven DE, Nagy G, Nagy E. Low Efficacy of Antibiotics Against Staphylococcus aureus Airway Colonization in Ventilated Patients. Clin Infect Dis. 2017;64(8):1081-1088. doi: 10.1093/cid/cix055.

5. Cillóniz C, Cardozo C, García-Vidal C. Epidemiology, pathophysiology, and microbiology of communityacquired pneumonia. Ann Res Hosp. 2018;2(1).

6. Kolesnikova LI, Semyonova NV, Grebenkina LA, Darenskaya MA, Suturina LV, Gnusina SV. Integral indicator of oxidative stress in human blood. Bull Exp Biol Med. 2014;157(6):715-7. doi: 10.1007/s10517-014-2649-z

7. Serebrovska Z, Swanson RJ, Portnichenko V, Shysh A, Pavlovich S, Tumanovska L, et al. Anti-inflammatory and antioxidant effect of cerium dioxide nanoparticles immobilized on the surface of silica nanoparticles in rat experimental pneumonia. Biomed Pharmacother. 2017;92:6977. doi: 10.1016/j.biopha.2017.05.064.

8. Han J, Ma D, Zhang M, Yang X, Tan D. Natural antioxidant betanin protects rats from paraquat-induced acute lung injury interstitial pneumonia. Biomed Res Int. 2015;2015:608174. doi: $10.1155 / 2015 / 608174$.

9. Zarubina IV, Mokrenko EV, Bolehan AV, Shabanov PD. [Comparative anti-inflammatory and ergotropny activity metapro- that, a trekrezana and a polioksidoniya and their combinations at experimental bronchopulmonary inflammation at rats]. Medical Academic Journal. 2016;16(3):48-50.[Article in Russian].

10. Kolesnikova LI1, Semyonova NV, Grebenkina LA, Darenskaya MA, Suturina LV, Gnusina SV. Integral indicator of oxidative stress in human blood. Bull Exp Biol Med. 2014;157(6):715-7. doi: 10.1007/s10517-014-2649-z.

11. Darenskaya MA, Grebenkina LA, Sholokhov LF, Rashidova MA, Semenova NV, Kolesnikov SI, Kolesnikova LI. Lipid peroxidation activity in women with chronic viral hepatitis. Free Radical Biology \& Medicine. 2016;100(S1):192. 12. Shabanov PD, Zarubina IV, Mokrenko EV. [Pharmacology of trekrezan, a new immune modulator and adaptogen]. Reviews on Clinical Pharmacology and Drug Therapy. 2014;12(2):12-27. [Article in Russian].

13. Zarubina IV, Shabanov PD. Antioxidant Effect of Polyoxidonium and Metaprot during Bronchopulmonary Inflammation in Rats. Bull Exp Biol Med. 2015;160(2):234-7. doi: 10.1007/s10517-015-3137-9.

14. Shabanov PD, Mokrenko EV. [Anti-inflammatory and immune stimulating effects of trekrezan in treatment of inflammatory and degenerative damages of the smooth parodont tissue]. Reviews on Clinical Pharmacology and Drug Therapy. 2015;13(2):34-42. [Article in Russian].

15. Mokrenko EV, Shabanov PD. [Treatment of inflammatory and degenerative damages of the smooth parodont tissue with tooth pastes in rats]. Pediatr. 2015;6(2):66-70. [Article in Russian].

16. Shabanov PD, Mokrenko EV. [The new immunomodulator and adaptogen trekrezan as a means of prevention and treatment of colds inflammatory diseases]. Vestnik Smolenskoj gosudarstvennoj medicinskoj akademii. 2014;13(2):61-65. [Article in Russian].

17. Yan T. Role of anti-inflammatory cytokines in pathogenesis of pediatric mycoplasma pneumoniae pneumonia. J Biol Regul Homeost Agents. 2016;30(2):541-5.

18. Berezhnaya NM. [Cytokine network regulation in pathology: rapid progress in knowledge and inevitable questions]. Cytokines and Inflammation. 2007;2(6):26-34. [Article in Russian].

19. Vasconcellos ÂG, Clarêncio J, Andrade D, Cardoso MA, Barral A, Nascimento-Carvalho CM. Systemic cytokines and chemokines on admission of children hospitalized with community-acquired pneumonia. Cytokine. 2018;107:1-8. doi: 10.1016/j.cyto.2017.11.005.

20. Shabanov PD, Mokrenko EV. [Condition of the oxidative status of blood and tissues in inflammatory degenerative damage of soft territorial tissues in rats after application of toothpases and their separate components]. Medical Academic Journal. 2015;15(2):55-61. [Article in Russian].

21. Volozhin AI, Mokrenko EV. [The relationship of the mechanical properties of the dentoalveolar complex to the status of the bone tissue in traumatic occlusion]. Stomatologiia (Mosk). 1991;(5):14-7. [Article in Russian].

22. Kolesnikova LI, Darenskaya MA, Semenova NV, Grebenkina LA, Suturina LV, Dolgikh MI, Gnusina SV. Lipid peroxidation and antioxidant protection in girls with type 1 diabetes mellitus during reproductive system development. Medicina (Kaunas). 2015;51(2):107-11. doi: 10.1016/j. medici.2015.01.009.

*Corresponding author: Marina A. Darenskaya, PhD, ScD. Scientific Centre for Family Health and Human Reproduction Problems, Irkutsk, the Russian Federation. E-mail: marina darenskaya@inbox.ru 
23. Guo W, Zhang TQ, XU YS, \& Liu FJ. The study on cytokines of bronchoalveolar lavage fluid in children with mycoplasma pneumoniae pneumonia. Tianjin Medical Journal. 2018;46(6):648-651.

24. Ostanin AA, Leplina OYu, Shevela EYa, Chernykh ER, Konenkov VI. [The assessment of cytokine pattern in patients with severe sepsis using the bio-plex-protein assay system]. Cytokines and Inflammation. 2004;1(3):20-27. [Article in Russian].

25. Varfolomeev E, Vucic D. Intracellular regulation of TNF activity in health and disease. Cytokine. 2018;101:26-32. doi: 10.1016/j.cyto.2016.08.035.

26. Darenskaya MA, Rychkova LV, Kolesnikov SI, Gavrilova OA, Kravtsova OV, Grebenkina LA, Kolesnikova LI. Oxidative stress parameters in adolescent boys with exogenous-constitutional obesity. Free Radical Biology \& Medicine. 2017;112:129-130.

27. Mehta AK, Gracias DT, Croft M. TNF activity and T cells.
Cytokine. 2018;101:14-18. doi: 10.1016/j.cyto.2016.08.003. 28. Taher MY, Davies DM, Maher J. The role of the interleukin (IL)-6/IL-6 receptor axis in cancer. Biochem Soc Trans. 2018;46(6):1449-1462. doi: 10.1042/BST20180136.

29. Bielen K, 's Jongers B, Malhotra-Kumar S, Jorens PG, Goossens H, Kumar-Singh S. Animal models of hospital-acquired pneumonia: current practices and future perspectives. Ann Transl Med. 2017;5(6):132. doi: 10.21037/ atm.2017.03.72.

30. Ershova OA, Bairova TA, Kolesnikov SI, Kalyuzhnaya OV, Darenskaya MA, Kolesnikova LI. Oxidative Stress and Catalase Gene. Bull Exp Biol Med. 2016;161(3):400-3. doi: 10.1007/s10517-016-3424-0.

31. Kolesnikova LI, Kolesnikov SI, Korytov LI, Suslikova MI, Darenskaya MA, Grebenkina LA, Kolesnikova LR. Oxidative Stress as a Mechanisms of Reduced Glucose Absorption under Conditions of Immobilization Stress. Bull Exp Biol Med. 2017;164(2):132-135. doi: 10.1007/s10517-017-3941-5. 